\title{
Article \\ 1D and Map-Based Modeling Approaches for Railway Compression Ignition Engine in NRTC Application
}

\author{
Giuseppe Di Luca ${ }^{1, *(\mathbb{C})}$, Massimiliano Muccillo ${ }^{2}$ (), Giovanni Giardiello ${ }^{2}$, Alfredo Gimelli ${ }^{2}$ (I) \\ and Gabriele Di Blasio ${ }^{1}$ (I)
}

1 Institute of Sciences and Technologies for Sustainable Energy and Mobility (STEMS), National Research Council, 80125 Napoli, Italy; gabriele.diblasio@stems.cnr.it

2 Department of Industrial Engineering, University of Naples Federico II, 80125 Napoli, Italy; massimiliano.muccillo@unina.it (M.M.); giovanni.giardiello@unina.it (G.G.); gimelli@unina.it (A.G.)

* Correspondence: giuseppe.diluca@stems.cnr.it

Citation: Di Luca, G.; Muccillo, M.; Giardiello, G.; Gimelli, A.; Di Blasio, G. 1D and Map-Based Modeling Approaches for Railway Compression Ignition Engine in NRTC Application. Appl. Sci. 2022, 12, 2665. https://doi.org/10.3390/ app12052665

Academic Editor: Talal Yusaf

Received: 23 December 2021

Accepted: 28 February 2022

Published: 4 March 2022

Publisher's Note: MDPI stays neutral with regard to jurisdictional claims in published maps and institutional affiliations.

Copyright: (C) 2022 by the authors. Licensee MDPI, Basel, Switzerland. This article is an open access article distributed under the terms and conditions of the Creative Commons Attribution (CC BY) license (https:// creativecommons.org/licenses/by/ $4.0 /)$.
Abstract: Internal combustion engine-driven railway vehicles play an important role in the sector even today, due to the incomplete electrification of railway routes. However, stringent COP26 environmental rules are driving manufacturers and the scientific community to study more complex or alternative propulsion systems. Therefore, the design of new powertrains is becoming more challenging. Affordable, along with robust, development tools are fundamental for their development and optimization. In this framework, numerical simulation can represent an effective instrument to face these requirements. The proposed study assesses the accuracy of different modelling approaches for the same engine. In particular, a detailed 1D model, a simplified 1D model and a map-based model are compared. Although studies on engine simulation are available in the technical literature, the novelty introduced with this work is the assessment of accuracy and computational times of the engine models, considered by performing the new emission standard Non-Road Transient Cycle (NRTC), which is applied to a specific field such as Heavy Duty (HD) Compression Ignition (CI) engines for railway applications. This study provides new and quantitative results rarely available in the specific literature. The results show that the simplest model, despite its lower accuracy, maintains good predictive results in terms of cumulative fuel consumption and cumulative nitric oxide $\left(\mathrm{NO}_{\mathrm{x}}\right)$ emissions over the cycle considered. In particular, the difference in terms of fuel consumption for the map-based model is within 5\% compared with the more detailed models. Moreover, the computational effort required by the simplest model is three orders of magnitude lower compared with the more detailed model. Therefore, as the simulation run-time is the priority, the simplest modeling approach is suitable for the evaluation of the global performance, in view of a more complex systems simulation, such as a hybrid powertrain.

Keywords: thermo-fluid dynamic simulation; map-based engine model; model accuracy; non-road transient cycle; heavy-duty diesel engine; real-time factor

\section{Introduction}

Currently, in many countries in Europe, the degree of railway electrification is higher than $50 \%$. For example, in Sweden, Italy and Austria the degree of electrification ranges between $68 \%$ and $71 \%$ for the complete rail network [1]. The railway network is rarely completely electrified, due to the inconvenient cost-benefit ratio of the electrification process in some rural or mountain sections of the railway network. Additionally, there are areas where electrification is very complex (i.e., harbors, loading tracks, etc.) [2]. As stated in [1], the average value of electrification in the European Union (EU) (considering 27 member states) is around $52 \%$. In later years, this value has remained fairly constant, as remarked in [3] and [4]. For this reason, in some countries, regional traffic or traffic on low utilization lines are covered by diesel trains. Generally, they are either single coaches or fixed coupled 
coaches consisting of two or three power cars. Each power car is driven by one medium power diesel engine, which ranges between 250 and $560 \mathrm{~kW}$, and is often derived from trucks or industrial engines [5]. In this case, the main concerns are regarding the harmful pollutant particulate matter $(\mathrm{PM})$ and $\mathrm{NO}_{x}[6]$ and the growing amount of greenhouse gas (GHG) emissions, such as carbon dioxide $\left(\mathrm{CO}_{2}\right)$, due to the combustion of fossil fuels [7]. According to the European Environment Agency (EEA), $\mathrm{NO}_{x}$ and $\mathrm{PM}$ emissions from the rail sector account for $1-1.5 \%$ of the total emissions from all transport sectors and, thus, have a small contribution compared to other sources of pollutant emissions [8]. However, to meet the stringent COP26 environmental rules [9], the task of decreasing the consumption of fossil fuel, the requirement of exhaust-free stations and the reduction of pollutant emissions is still significant. Additionally, the application of the actual NRMM Directive [10] to rail diesel vehicles and the upcoming new stricter emission standard named Stage V significantly raise the importance of developing new powertrains in terms of design, performance, fuel consumption, emissions, etc. In this context, numerical simulation represents valid support in engine optimization or the development of complex powertrain architectures. This aspect becomes more relevant with alternative forms of propulsion, such as hybrid propulsion, including several subsystems or components (e.g., gearbox, electrical motors, batteries, etc.). One of the greatest challenges in numerical simulation is to establish the Pareto optimum in terms of model accuracy and computational time [11]. This challenge is particularly true for engine modelling, where a different level of detail can be considered.

In particular, as stated in [12], the level of detail of a model can be defined as "an assessment of the extent to which the observable system elements and the assumed system relationships are included in the model", where "level of detail" refers to the system that the model represents. As for the engine modelling, the level of detail depends on the phenomenon to be analyzed and on the $\mathrm{x}$-D CFD simulation level approach.

The most accurate approach is the 3D CFD, which is generally used for modelling flow dynamics in intake and exhaust systems of internal engines, as well as for modelling in-cylinder phenomena such as gas flow through the intake and the exhaust valves, direct fuel injection, mixture formation, combustion process, etc. Due to the significant increase of the computational time, this approach is usually applied to investigate the specific phenomenon, limited engine components or confined volumes, rather than the whole engine [13]. To avoid engine system-level perspective, 1D simulation is used. In this case, the analysis and verification of air-path design concepts, including the prediction of the engine transient response, can be conducted. Contrary to 3D CFD models, 1D models predict the distribution of gas properties in only one direction, the axis of primary flow in the air path. 1D engine simulation packages [14] usually include some form of combustion model and the effects of heat transfer [15]. In refs. [16,17], the authors applied the 1D approach for a fuel-saving analysis, adopting an innovative valvetrain system. Ammendola et al. [18] proposed a methodology to calibrate a 1D model, starting from limited test bench data, with a view to detect, preliminarily, the effect of geometric changes or control parameter variations on engine performance. In 1D models, flow components are referred to as templates to define their geometric characteristics by a few parameters. Devices like turbochargers and injectors can be integrated into the flow network through modules that replicate their interactions with the flow during simulation [19]. A detailed 1D engine model offers information over hundreds of sub-volumes in an engine performance simulation, but the computational time can take up to several orders of magnitude more than in real-time. When the simulation speed is of priority, a detailed model can be converted into a simplified 1D model in which volumes are lumped together, where possible, to enable a larger timestep and solve fewer sub-volumes. In this case, a reasonable trade-off between computational effort and accuracy is chosen as a function of the application. These kinds of models can also be designed to run in real-time for Hardware in the Loop (HiL) applications at the expense of certain details, e.g., wave dynamics, that might not reflect the final results [20]. The simplest approach to describe the entire 
engine in a data-driven manner is through a map-based engine model which comprises the entire engine behavior into maps. With the proper maps, vehicle performances and fuel consumption can be reasonably assessed for various legislation cycles and drivetrain configurations [21]. In ref. [22], the authors applied a map-based approach to model an innovative thermo-electric propulsion system for marine applications, in order to perform optimal management strategies for emissions reduction and battery pack durability. The map-based approach is also suitable to model stationary applications such as innovative micro-combined heat and power [23]. In the map-based modelling approach, engine components are not modelled, and the computational requirements are low. To the authors' knowledge, although studies on engine simulation are available in the specific literature, the novelty introduced in this work is firstly related to the specific field of application. Further to this point, there is a poor number of works in the literature on compression ignition engines for railway applications. In particular, the implementation of the NonRoad Transient Cycle emission standard for these types of engines has not been thoroughly investigated. Furthermore, the aim of this work is the evaluation of a reasonable tradeoff between model accuracy and computational time among three different modeling approaches for the same engine performing the homologation cycle mentioned above. The purpose of this analysis is to find the right compromise in terms of the computational effort and predictive accuracy of the proposed models in view of more complex numerical applications for future authors' activities involving railway powertrains. The remainder of this paper is organized as follows. In the first part, an outline of the emission test cycle is presented. A specific section will be reserved to illustrate engine models and the application of the transient cycle to them. In the last part of the paper, the main outcomes, with suggestions for further advances, are discussed.

\section{Materials and Methods}

\subsection{Emission Test Cycle}

To make the emission results representative of real driving conditions, a new transient test procedure, named NRTC, was developed for the emission measurement. The new test, introduced in cooperation with the US EPA (United States Environmental Protection Agency, Washington, DC, USA) and European Commission, needed to be used in parallel with the prior steady-state schedule, ISO $8178 \mathrm{C}$, referred to as the Non-Road Steady Cycle (NRSC) [10]. The ISO 8178 is an international standard designed for non-road engine applications which include a collection of different steady-state engine dynamometer test cycles (designated as C1, C2, etc.) for different classes of engines and equipment. Each of these cycles represents a sequence of several steady-state modes with different weighting factors. The $\mathrm{C} 1$ homologation test points are shown in terms of speed, torque and weighting factor in Table 1 [10].

Table 1. Weighting Factors of C1 ISO 8178 Test Cycle.

\begin{tabular}{ccccccccc}
\hline & \multicolumn{3}{c}{ Rated Speed } & \multicolumn{3}{c}{ Intermediate Speed } & \multicolumn{2}{c}{ Idle } \\
\hline Torque & 100 & 75 & 50 & 10 & 100 & 75 & 50 & 0 \\
\hline Weight & 0.15 & 0.15 & 0.15 & 0.10 & 0.10 & 0.10 & 0.10 & 0.15 \\
\hline
\end{tabular}

The NRTC test procedure is a dynamic test for CI engines used in non-road machinery. It is characterized by the transient conditions in which speed and torque change dynamically. The test is considered one of the most stringent transient cycles since it has higher speed-load variations compared to other legislative transient cycles. The NRTC test procedure lasts about $1238 \mathrm{~s}$, and the EU directive also provides the dynamic sequence of the so-called normalized speed and normalized torque to be applied to the dynamometer during the test procedure (Figure 1). 

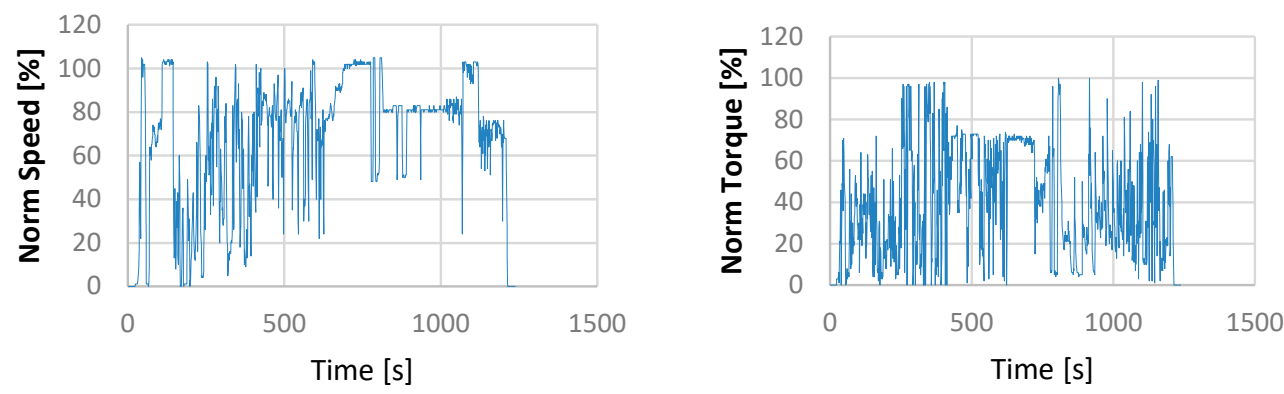

Figure 1. NRTC: Normalized Speed; Normalized Torque.

It is worth underlining that the NRSC shall be used for all stages, whereas the NRTC test is not mandatory for stage IIIA. The transient procedure is obligatory for stages IIIB/IV and the upcoming Stage V. Table 2 reports the emission limits for the past, current and upcoming standards [10].

Table 2. Evolution of the emission standard limits for non-road diesel engines in the power range $130-560 \mathrm{~kW}$.

\begin{tabular}{ccccccc}
\hline Stage & Date & \multicolumn{5}{c}{ Emissions (g/kWh) } \\
\hline & & CO & HC & NO $_{\mathbf{x}}$ & PM & PN \\
\hline IIIB & 01.2011 & 3.50 & 0.19 & 2.0 & 0.025 & - \\
IV & 01.2014 & 3.50 & 0.19 & 2.0 & 0.025 & - \\
V & 2021 & 3.50 & 0.19 & 2.0 & 0.015 & $1 \times 10^{12}$ \\
\hline
\end{tabular}

The simulations performed in this study were carried out in consideration of the NRTC obtained after the "denormalization procedure" of the engine speed and torque. This procedure can be found in [24]. Once denormalized, the dynamic sequence of the engine speed and torque appears, as shown in Figure 2.
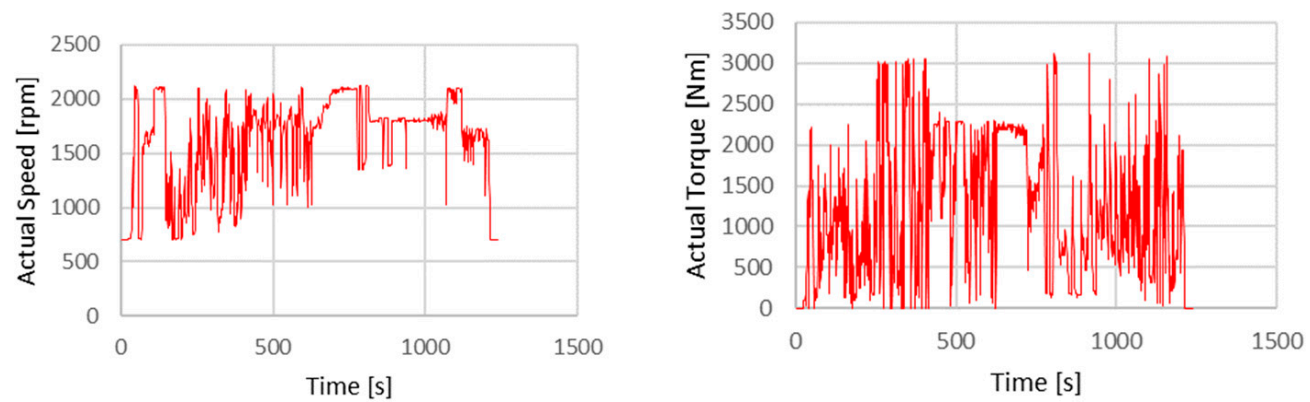

Figure 2. NRTC: Actual Speed; Actual Torque.

\subsection{Engine Characteristics and Modeling}

The engine used as a reference in this study is a $560 \mathrm{~kW}$ HD diesel engine, applied in railcars or Diesel Multiple Unit (DMU) applications. Specifically, it is a V8 direct-injection four-stroke engine, with a total displacement of $20 \mathrm{dm}^{3}$, turbocharged. The main engine characteristics are reported in Table 3.

The engine is made up of two in-line four-cylinder banks with a bank angle of $90^{\circ}$. Each cylinder bank is fed by a turbocharger system. 
Table 3. Engine characteristics $[25,26]$.

\begin{tabular}{cc}
\hline Engine Code & V08 ENT \\
Power & $560 \mathrm{~kW}$ at $2100 \mathrm{rpm}$ \\
Torque & $3200 \mathrm{Nm}$ at $1400 \mathrm{rpm}$ \\
Idle speed & $700 \mathrm{rpm}$ \\
No. of cylinder and arrangement & $8-\mathrm{V} 90$ \\
Valves & 4 per cylinder \\
Air system & Supercharged and aftercooled \\
Firing order & $1-3-7-2-6-5-4-8$ \\
Bore & $145 \mathrm{~mm}$ \\
Stroke & $152 \mathrm{~mm}$ \\
Compression Ratio & $17.4: 1$ \\
IVO/EVC & $27.5^{\circ} \mathrm{BTDC} / 53.5^{\circ} \mathrm{ABDC}$ \\
EVO/EVC & $60^{\circ} \mathrm{BBDC} / 22.5^{\circ} \mathrm{ATDC}$ \\
\hline
\end{tabular}

To model the engine, the 1D modelling approach was used. In particular, the reference model was derived from a previous authors' study [26], where a simulation model of a railway diesel engine was developed and validated. This model was able to perform the NRSC ISO $8178 \mathrm{C} 1$ homologation cycle in pre-defined stationary speed-load points. The reference engine model is defined, in terms of "depth" of detail, as a "detailed 1D model". In this modeling approach, the whole engine layout is discretized and modelled on the base of the real sub-components characteristics. In Figure 3, a scheme of the detailed model is depicted. As shown, the inlet and outlet conditions respectively refer to the ambient conditions and to the exhaust gases state on exit from the turbines. All ducts, pipes referring to the legend in Figure 3, are joined via orifice junction connections. The orifice junction can be used to specify a flow restriction by setting the orifice diameter restriction smaller than the diameter of the mating elements. Furthermore, the solver uses the smaller diameter of the joined elements if there is no restriction to take into account. In all pipes, the flow model is based on the solution of the one-dimensional continuity (1), energy (2) and momentum (3) equations [27] that characterize the wave propagation phenomena:

$$
\begin{gathered}
\frac{d m}{d t}=\sum \dot{m} \\
\frac{d(m e)}{d t}=-p \frac{d V}{d t}+\sum(\dot{m} H)-h A_{s}\left(T_{\text {fluid }}-T_{\text {wall }}\right) \\
\frac{d \dot{m}}{d t}=\frac{d p A+\sum(\dot{m} u)-4 C_{f} \frac{\rho u|u|}{2} \frac{d x A}{D}-K_{p}\left(\frac{1}{2} \rho u|u|\right) A}{d x}
\end{gathered}
$$

This means that all of the quantities are averages across the flow direction. The cylinders have been modelled by means of the "filling-emptying method". In regards to turbomachinery, both compressor and turbine have been described as simple templates based on the thermodynamics equations. In particular, for the turbine, the output power is calculated using Equation (4).

$$
P_{t}=\dot{m} \frac{k-1}{k} R T_{i n t, T}\left(1-\frac{1}{\beta_{t}^{\frac{m-1}{m}}}\right)
$$

In Equation (4), $\dot{m}$ is the mass flow, $R$ represents the gas constant, $\beta_{t}$ is the expansion ratio, $k$ is the gas heat specific ratio, $T_{i n t, T}$ the temperature upstream the turbine and $m$ the polytropic exponent.

For the compressor, the mass flow rate $\dot{m}_{c}$ and outlet temperature are calculated from the inlet temperature $\left(T_{i n t, C}\right)$, compression ratio $\beta_{c}$ and efficiency, starting from the input power $P_{c}$ calculated through Equation (5), considering that $P_{t}=P_{c}$. 


$$
P_{c}=\dot{m}_{c} \frac{k-1}{k} R T_{i n t, C}\left(\beta_{c}^{\frac{m_{c}-1}{m_{c}}}-1\right)
$$

where $m_{c}$ represents the polytropic exponent.

More details on the flow model and solver used in this modeling approach can be found in [28]. The combustion model is based on a predictive approach, able to predict the combustion rate and, to some extent, the associated emissions for direct-injection diesel engines with single and multi-pulse injection events. A more detailed description of the model is reported in [28].

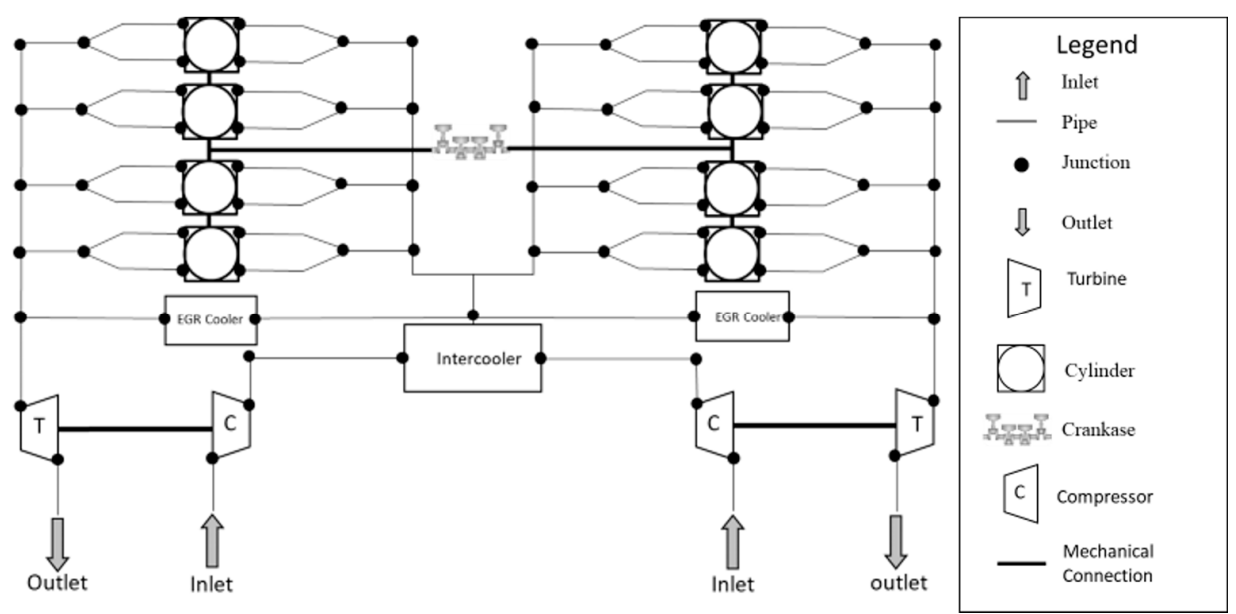

Figure 3. Detailed model of HD diesel engine.

As previously introduced, the detailed 1D model was able to run in pre-defined stationary speed-load points. To perform a transient cycle throughout the simulations, it is necessary to know the engine behavior, not only in pre-defined points but in the whole operating range. For these reasons, some changes to the original model were necessary. Firstly, due to the lack of data at partial load conditions, the information necessary to develop the engine maps was obtained via simulations, starting from the validated model. From the experimental full-load power curve, several operating points at partial loads were identified, matching the percentage of load to the percentage of power. With this approach, the partial load map was identified. This map is composed of 70 engine operating points, as shown in Figure 4.

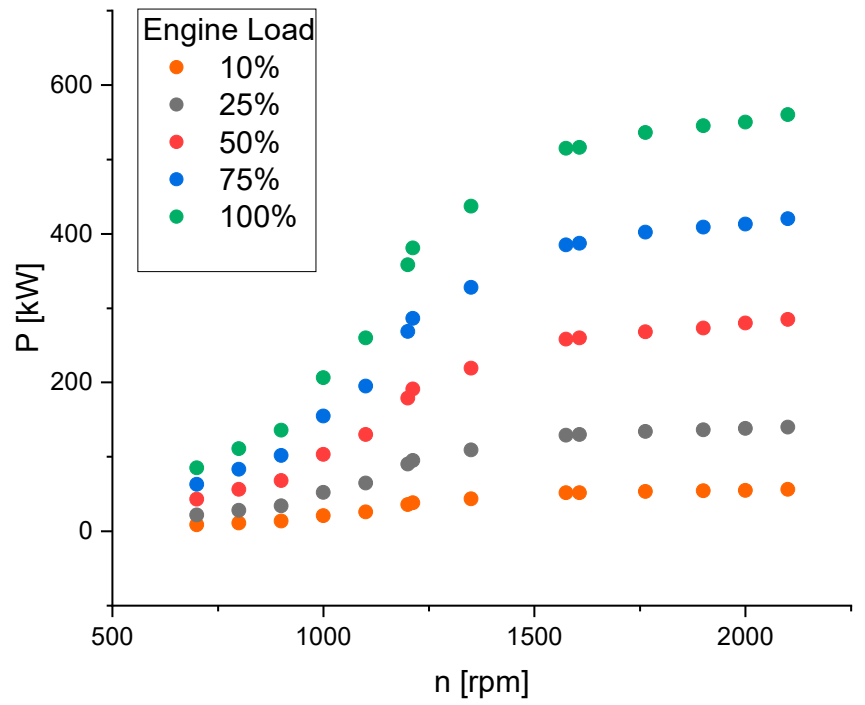

Figure 4. Speed-Power-Load [\%] output map. 
In these points, the requested fuel mass was assessed by an injection controller implemented into the detailed model to reach the power target, as depicted in Figure 5. The desired amount of fuel was calculated, taking into account several physical quantities of the engine (e.g., fuel energy, engine displacement, etc.), in addition to the instantaneous values of the engine rpm. The controller required, in addition, the instantaneous values of the intake airflow, so it could calculate the amount of fuel, having, as a limit, a minimum value of Air to-Fuel ratio. This value was set to 17. It is worth highlighting that the minimum value obtained during the simulations was 19.6 (lambda 1.36), a typical value for diesel engines. When performing the simulation, each timestep is constrained, according to the Courant condition. This condition is necessary to avoid an unstable solution. Further details have been provided in Section 3.1.

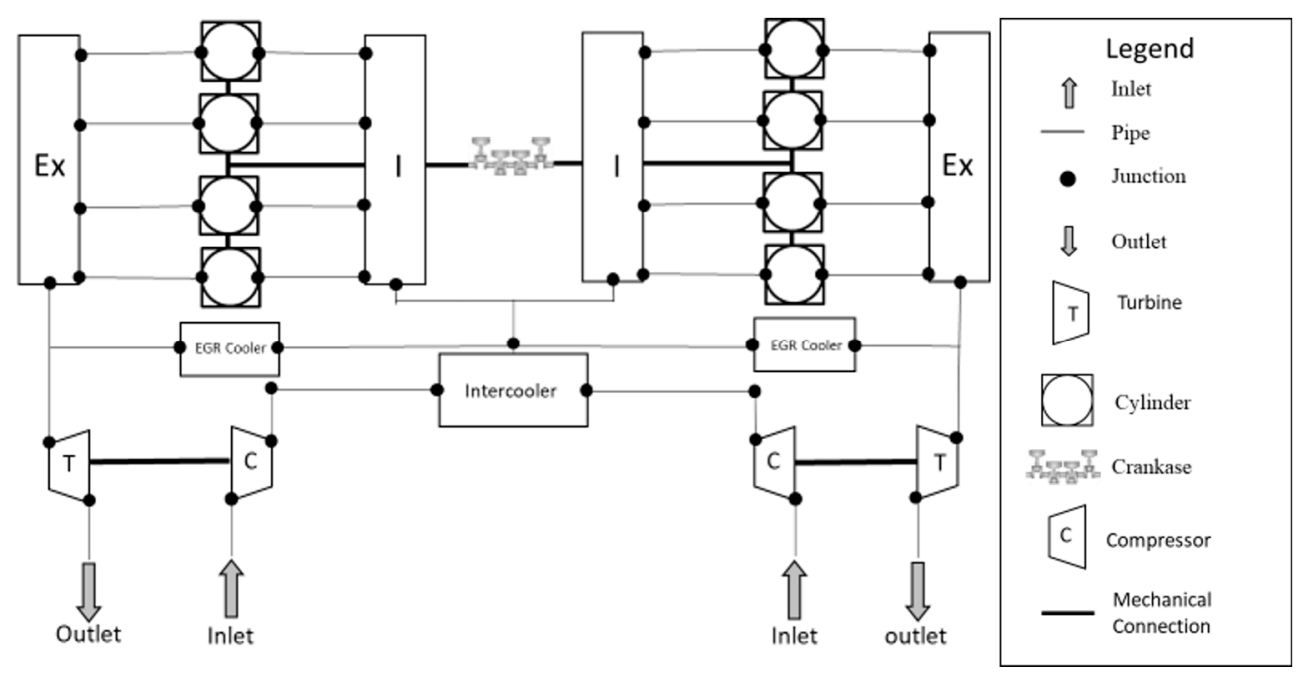

Figure 5. Simplified 1D scheme of HD Diesel Engine.

At the end of the simulations in the identified operating points, once defined the target fuel mass, the operative engine maps were obtained by interpolating all points.

To perform the simulation of the NRTC, all of the inputs, depending on the operating conditions, have to change using either some form of look-up or a predictive model to account for the changes. Thus, all of the input maps (injection parameters, thermodynamic conditions, actuator positions, etc.) were derived and grouped into maps in order to also complete the modelling of a "map-based" model able to run transient cycles. Instant by instant, the simulation software via interpolation can calculate the desired input when performing the transient cycle. The quantity of the fuel to be injected time after time was defined by a look-up table as a function of the speed and load imposed by the NRTC. The load level and the engine rpm are those imposed by the NRTC after the denormalization procedure.

Finally, it was necessary to consider that the wall temperature in transient operations changes over time in pipes and flow-splits, as well as cylinders. Therefore, the thermal solver was set to transient mode.

The "Simplified 1D" model was derived from the detailed 1D model. The difference with the detailed model consists of considering the intake (I) and exhaust (Ex) plenum as a unique element, as highlighted in Figure 5. This approach permits a lower computational time at the expense of reducing the accuracy in the definition of the possible differences of in-cylinder intake and exhaust characteristics. The flow and combustion models are the same as the detailed model previously introduced.

The third level of engine model, in terms of "depth of details", considered in this work is the "map-based model". This simple approach consists of a "black box" based on performance maps and characteristics to be interpolated to describe engine behavior across the speed-load range. The performance maps considered are a 2D characteristic 
map of the Brake Mean Effective Pressure (BMEP), related to engine speed and load, and 2D characteristic maps of fuel and airflow rates, both related to engine speed and BMEP. As secondary maps, the $2 \mathrm{D}$ maps of $\mathrm{NO}_{\mathrm{x}}, \mathrm{CO}, \mathrm{CO}_{2}$ and $\mathrm{HC}$ emissions were considered. These maps relate brake-specific emissions to engine speed and BMEP and allow for the calculation of instantaneous emission rates during simulations. All of the maps previously introduced are strictly associated with and generally provided by the OEMs, since they are obtained experimentally. The testing phase is both time-consuming and expensive. For this study, since the physical engine at the test bench was not available, the performance maps were obtained via a simulation approach, starting from the experimentally validated "detailed 1D model" previously introduced. Through a specific procedure, available in [28], and using a Full Factorial DoE, the engine performance maps were obtained.

\section{Results and Discussion}

This paragraph is divided into three sections. The first shows the Simplified 1D model calibration results and its accuracy in comparison with the detailed model. Once the implementation of the transient NRTCs was performed into the models listed, simulations were carried out. The second and third sections show the simulation results in terms of predictive accuracy and computational effort among the proposed models.

\subsection{Simplified 1D Model Calibration Results and Accuracy Check}

The Simplified 1D model was calibrated into the same steady points in which the detailed model was validated. The calibration process was composed of several steps. At each timestep, the matching was verified with the original simulation result. The main results are shown below.

During the conversion process, especially where the volumes are joined (intake and exhaust plenums), it is necessary to identify the components which can restrict the timestep, especially the exhaust manifold due to the high gas velocities that occur in it. To ensure the right accuracy in comparison to the detailed model, both in terms of pressure and temperature, a recalibration of the duct diameters or heat transfer multiplier must be varied, respectively. An example of the recalibrated heat transfer multiplier of the turbine inlet and outlet is reported in Figure 6.

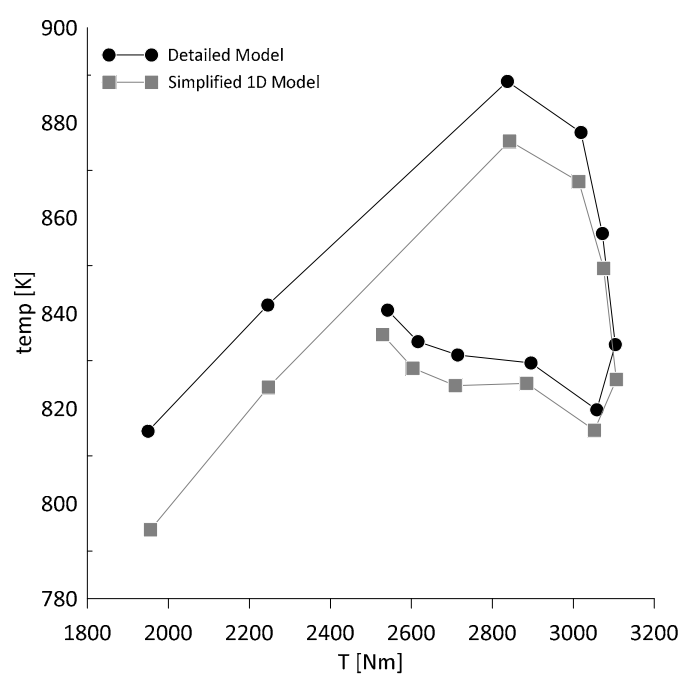

(a)

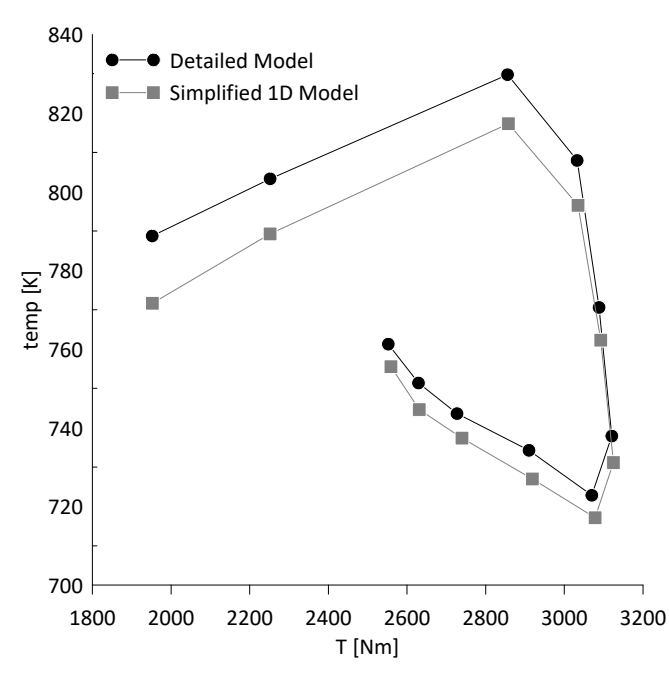

(b)

Figure 6. Exhaust manifold: Inlet (a) and Outlet (b) temperature. 
As seen, despite slight deviations between the trends, the results can be considered satisfactory. After the calibration process to assess the accuracy of the simplified 1D model, some key parameters have been considered and compared with those of the detailed model. Indeed, in terms of "performance", as can be seen in Figure 7, power, IMEP and fuel consumption can be considered comparable.

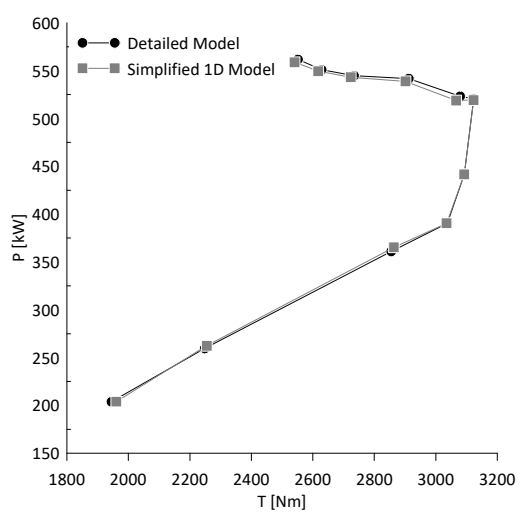

(a)

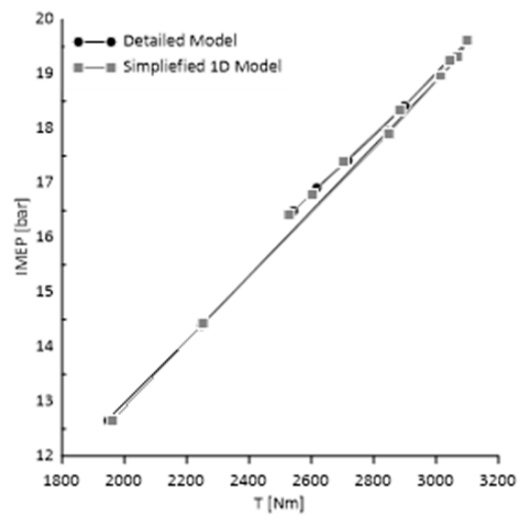

(b)

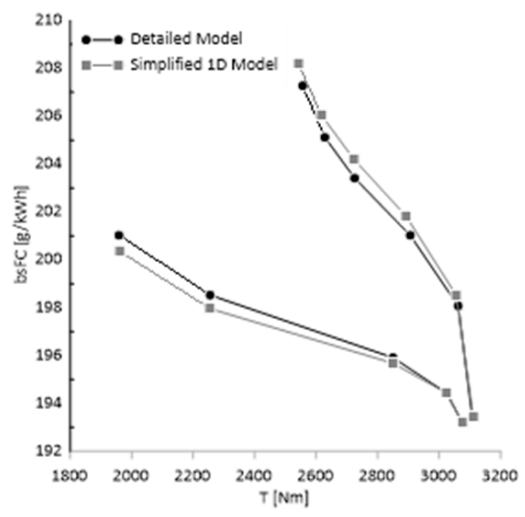

(c)

Figure 7. (a) Power, (b) IMEP, (c) bsFC Comparison.

Figure 8 shows the comparison in terms of the timesteps in the crank angle units (a) and in time (b). As expected, the simulation run-time of the Simplified 1D Model was lower than that of the more detailed model, due to an increased value of the timestep. This can be related to the reduced number of sub-volumes that enable a larger timestep.

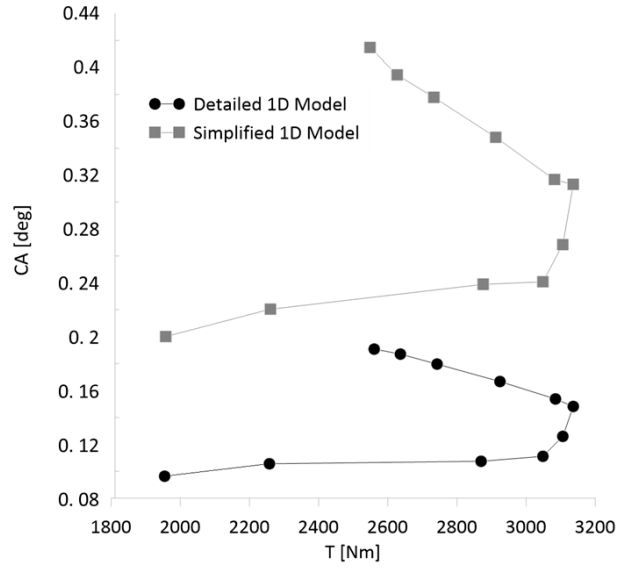

(a)

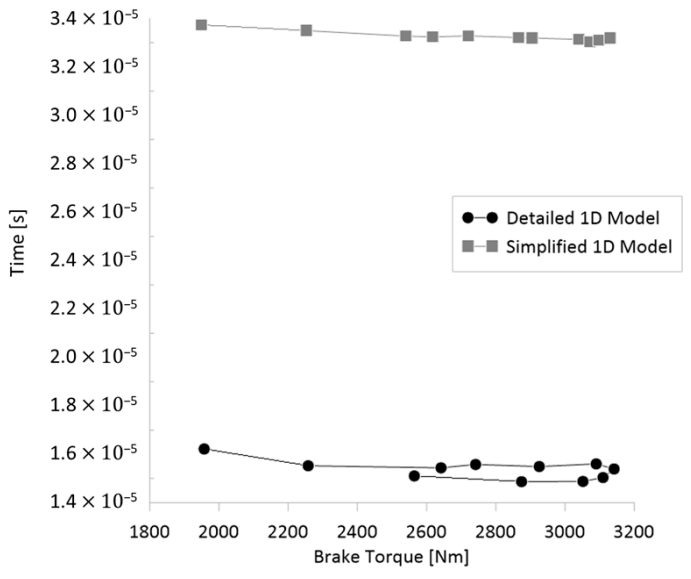

(b)

Figure 8. (a) Timestep comparison in crank angle resolution; (b) Timestep comparison in time.

In particular, to have stable solver operations, the timestep and discretization length must meet the Courant condition:

$$
\frac{\Delta t}{\Delta x}(|u|+c) \leq 0.8 \times m
$$

The user-imposed maximum timestep for the detailed model is 0.2 crank angle degree (CAD), while for the Simplified 1D Model, the timestep has been set to a "def" value, which means, for the solver used (explicit method), that the maximum timestep allowed is 1 CAD. With this constraint, in the Simplified 1D model, performing the NRTC simulation, the timestep is dynamically restricted according to condition (6). Following the Courant criteria, as the explicit solver is used, higher local velocities imply a smaller crank angle 
timestep for numerical stability. As the local velocity $\Delta x / \Delta t$ increases and the discretization length $\Delta x$ is the same, the crank angle timestep $\Delta t$ needs to be refined in order to meet the Courant condition. Thus, the maximum value reached is $0.42 \mathrm{CAD}$ as shown in Figure 8 . Nevertheless, the timestep in each case is $50 \%$ larger than for the detailed model. Further to this point, the Simplified 1D Model is characterized by a lower computational requirement, ensuring good predictability since the predictive combustion model is unchanged. A further computational time reduction can be obtained, for example, for real-time application, by superimposing the combustion evolution traces.

\subsection{Predictive Analysis}

Figure 9 shows the BMEP comparison among the proposed models over the transient cycle considered. To estimate the accuracy of the engine models running NRTC, the Y1 (left) axis in the second row of Figure 9 shows the instantaneous errors, whereas the Y2 (right) axis shows the average errors compared with the NRTC target BMEP. In particular, the instantaneous error for the Map-based model shows some spikes, reasonably due to an incorrect interpolation of the performance map running the simulation. Nevertheless, for all of the considered models, the average errors over the transient cycle are within $6 \%$.

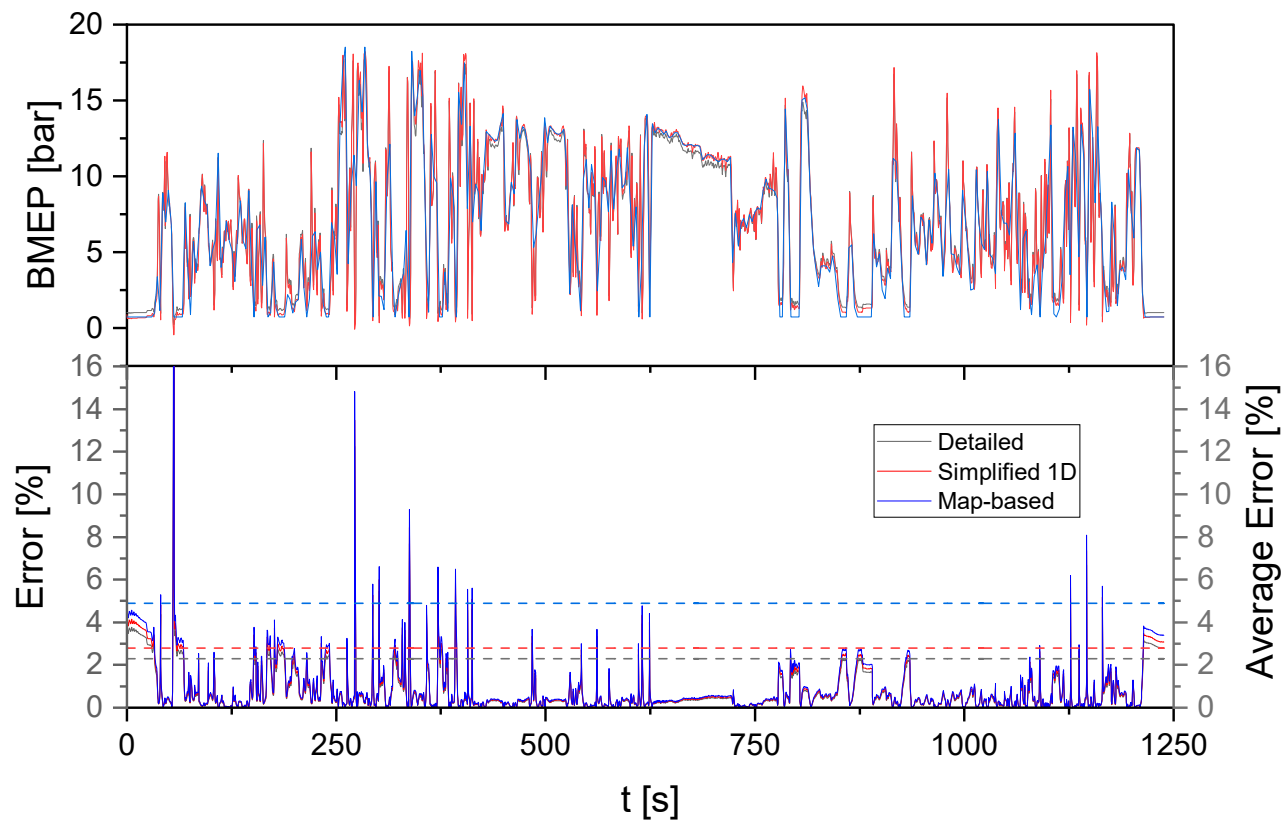

Figure 9. BMEP comparison.

From the emission point of view, for a more accurate prediction of pollutant emissions and to employ detailed chemical kinetics, more complex models are necessary and out of the scope of the work. However, this is not the purpose of the present work. Since the detailed Zeldovich mechanism is already implemented, and the in-cylinder temperature with a predictive model is quite well predicted, the $\mathrm{NO}_{x}$ emissions are considered instead.

First, a comparison between the detailed model and the fast-running model is made. As can be seen in Figure 10, the Simplified 1D Model overestimates the $\mathrm{NO}_{\mathrm{x}}$ emissions. The differences lay in the fact that the in-cylinder conditions are slightly different between the Simplified 1D Model and the detailed model, because, in the first case, the intake thermodynamic conditions are constant for all of the cylinders, while, in the second case, they are calculated for each cylinder. 


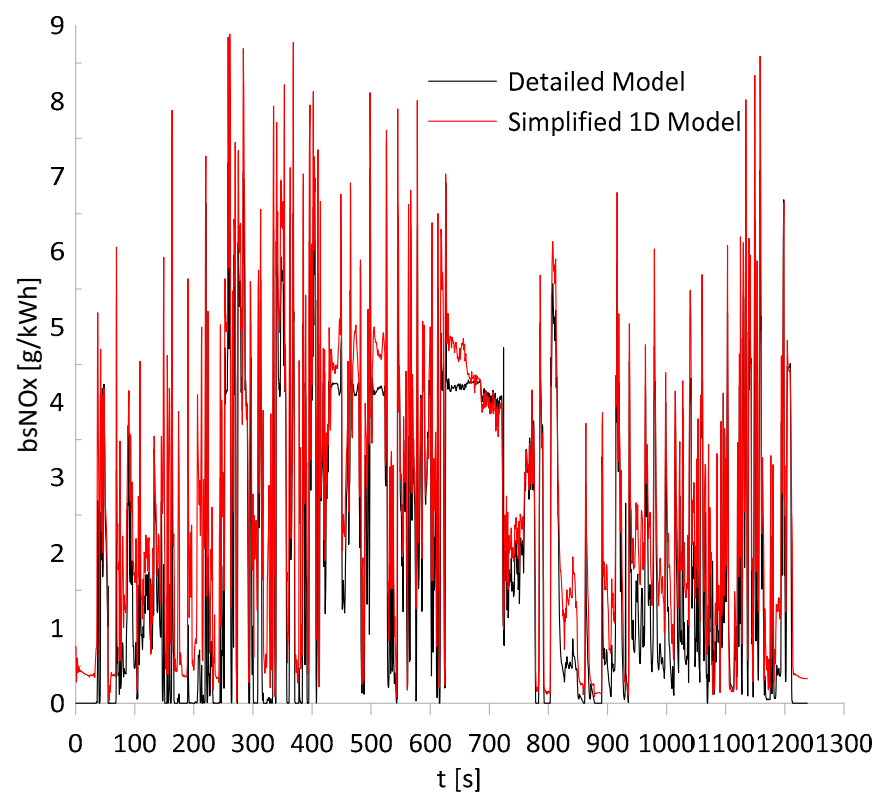

Figure 10. Brake specific $\mathrm{NO}_{x}\left(b_{s N O}\right)$ Comparison.

This trend is confirmed by comparing cumulative $\mathrm{NO}_{\mathrm{x}}$ emission results over the NRTC, as shown in Table 4. This step is necessary to also compare the map-based model, due to its cumulative $\mathrm{NO}_{\mathrm{x}}$ emission result.

Table 4. $\mathrm{NO}_{\mathrm{x}}$ emissions and fuel consumption results.

\begin{tabular}{ccccc}
\hline Model Type & $\begin{array}{c}\text { Cumulative } \mathbf{N O}_{\mathbf{x}} \\
\text { Emissions } \mathbf{( g )}\end{array}$ & $\begin{array}{c}\Delta \mathbf{N O}_{\mathbf{x}} \\
\mathbf{( \% )}\end{array}$ & $\begin{array}{c}\text { Cumulative Fuel } \\
\text { Consumption }(\mathbf{g})\end{array}$ & $\begin{array}{c}\Delta \text { Fuel } \\
\mathbf{( \% )}\end{array}$ \\
\hline Detailed 1D & 238 & $/$ & 14,500 & $/$ \\
Simplified 1D & 260 & +9.2 & 14,600 & +0.7 \\
Map-based & 267 & +12 & 14,036 & -3.2 \\
\hline
\end{tabular}

As can be seen, the map-based model, via interpolation, gives a cumulative $\mathrm{NO}_{\mathrm{x}}$ result of $267 \mathrm{~g}$, which is $12 \%$ higher than the value obtained via simulation with the detailed model. The result can be considered satisfactory, considering that a map-based model includes no chemical kinetics relationships. In terms of fuel consumption comparison, no relevant difference can be noticed between the simplified 1D Model and the detailed one. The difference in terms of fuel consumption for the map-based model is within $5 \%$ compared to the detailed one. Thus, it can be stated that lower accuracy models, such as the proposed map-based model, are suitable for the trends analyses, in terms of energy, $\mathrm{NO}_{x}$ emissions, fuel consumption, global and subsystems outputs, of complex powertrain systems.

\subsection{Computational Comparison: Real-Time Factor}

To compare the computational effort of the proposed models, the Real-Time (RT) factor is introduced. This parameter is defined as the ratio between the run-time of the simulation and the time span of the physical event. In this work, the physical event is represented by the NRTC, with a duration of $1238 \mathrm{~s}$. Table 5 summarizes the evaluated RT factors for the engine models proposed. As can be seen, the detailed model performed the NRTC in $285,522 \mathrm{~s}(\approx 79 \mathrm{~h})$, with an RT factor of about 230 . The simplified 1D model performed the same cycle in $59,312 \mathrm{~s}(\approx 17 \mathrm{~h})$, with an RT about of 50 , whereas the map-based model was in $1161 \mathrm{~s}$, with an RT of 0.9. It is worth underlining that all of the simulations were performed on a workstation with an Intel ${ }^{\circledR}$ i7 processor @ $3.8 \mathrm{GHz}$ and dedicated GPU to improve run-time simulation. 
Table 5. Real-Time factors of the proposed engine models.

\begin{tabular}{ccc}
\hline Model Type & Simulation Run-Time & RT \\
\hline Detailed 1D & 285,522 & 230 \\
Simplified 1D & 59,312 & $\approx 50$ \\
Map-based & 1161 & 0.9 \\
Map-based 10x & 115 & 0.09 \\
\hline
\end{tabular}

As shown in Table 5, the RT factor of the more detailed modeling approach is the highest. As expected, the simulation run-time rises. This is due to the computational demand necessary to solve the one-dimensional equations in the ducts per each timestep. Although the simplified 1D model allows for a larger timestep compared to the previous case by adopting a predictive combustion model, it is not adequate for HiL applications due to its overly high RT factor. The map-based model is characterized by an RT factor near the unit, so the simulation duration is similar to the physical event. In terms of the simulation run-time, the map-based model is roughly 250 times faster than the detailed model and about 50 times faster than the fast-running model performing NRTC. In this modeling approach, applying an integration timestep of $10^{-2} \mathrm{~s}$, the evaluated RT factor is 0.09 . Thus, the map-based model can be considered inexpensive in terms of computational requirements.

These results can be considered coherent with the literature findings in engine simulation in terms of simulation run-time. In particular, Figure 11 displays an RT comparison among different engine models, classified according to their level of detail and speed simulation.

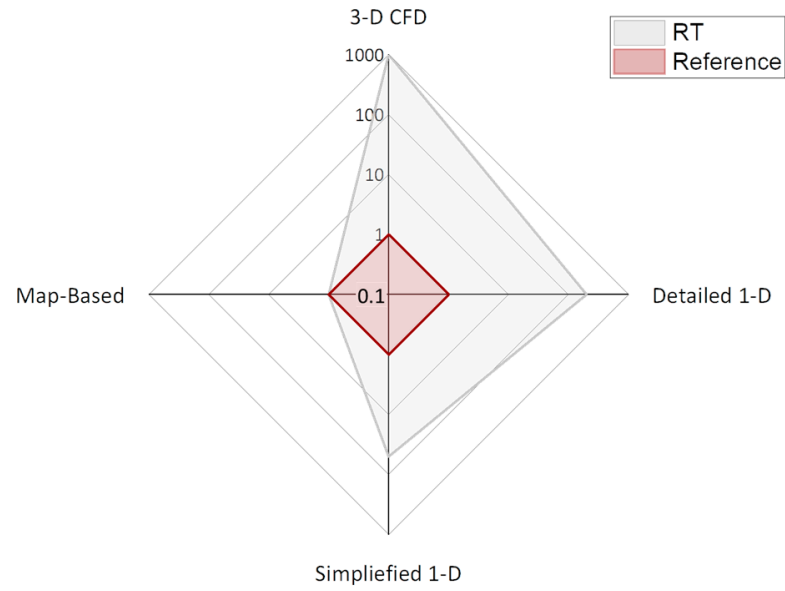

Figure 11. RT comparison.

As expected, 3D approaches can be considered time expensive due to their wellknown reputation in terms of accuracy [29]. The detailed 1D models can be characterized by different levels of details, and thus, the computational run time depends on it [30]. The RT factor and the accuracy of the simplified 1D models can be considered acceptable. As briefly discussed above, with the proper calibration, these models can perform a simulation more quickly, and thus, can also be suitable for HiL application [31]. When simulation speed is the priority and high details are not required, map-based models can help to get an overview of the engine performance with a fast simulation time and an RT near the unit, or even faster than real-time, as reported in Table 5. However, a detailed physical description of the individual engine component cannot be incorporated in these kinds of models, and their accuracy depends on the map-building process [32,33].

\section{Conclusions}

This study evaluates the computational effort and simulation output results among three engine models with different levels of detail. For this purpose, starting from a validated high-fidelity 1D model, two simplified models were proposed: a Simplified 
1D model and a non-dimensional one, built through operative maps to simulate engine behavior. To assess the differences among the listed models, numerical simulations were carried out, performing the NRTC standard after the cycle denormalization procedure.

The numerical results reported in this work have highlighted several key points and conclusions:

- To estimate the accuracy of the engine models running NRTC, the instantaneous errors and the average errors compared with the NRTC target BMEP were assessed. For all of the considered models, the average errors over the transient cycle are within $6 \%$.

- The simplified 1D model, after the calibration procedure, loses some details due to the lumped volumes. Nevertheless, it maintains a good accuracy compared to the more detailed model. In particular, in terms of fuel consumption, the error is within $1 \%$. The simplified 1D model is less computational-time expensive than the detailed one, due to its lower $\mathrm{RT} \approx 50$.

- A qualitative analysis of the $\mathrm{NO}_{\mathrm{x}}$ emission was carried out. The simplest approach, with no chemical kinetic equations implemented into it, achieved a good result in cumulative $\mathrm{NO}_{\mathrm{x}}$ prediction compared to the more complex models; the simulation results show a difference among the models, ranging in the interval $0-10 \%$.

- In terms of the cumulative fuel consumption prediction, the map-based model shows comparable results with the other models listed, with a maximum difference of about $3 \%$ with the high fidelity $1 \mathrm{D}$ model.

- $\quad$ By comparing the three models in terms of computational speed, the map-based model is 250 times and 50 times faster compared to the detailed and Simplified 1D model, respectively.

Based on the results above, since the predictive combustion model is unchanged, in order for the Simplified 1D Model to be adopted for HiL applications, the improvement of the calibration process by using an advanced optimization tool must be considered, ensuring multiple parameter variations to achieve the given target. The map-based model, notwithstanding its lower accuracy, shows good predictive results through numerical simulation in terms of the cumulative fuel consumption and $\mathrm{NO}_{\mathrm{x}}$ emissions performing a transient cycle. Moreover, it can be considered inexpensive in terms of computational demand due to its low RT factor. Thus, it is suitable in applications where computational speed is the priority, such as numerical simulations of complex hybrid architectures or HiL applications. In this regard, future activities will be oriented in using the most adequate approach by evaluating the differences for Hybrid, Diesel-Electric and powertrain applications.

Author Contributions: Writing-original draft, methodology, G.D.L.; Writing-review and editing, G.D.L. and M.M.; Software, G.D.L. and G.G.; Conceptualization, G.D.B.; Supervision, A.G. All authors have read and agreed to the published version of the manuscript.

Funding: This research received no external funding.

Acknowledgments: The authors would like to thank Ianora Stefano and Schiavo Mariano, who contributed to this study with their thesis works, and Rosario Moreschi, for the technical informatic contribution.

Conflicts of Interest: The authors declare no conflict of interest.

\section{Nomenclature}

$\begin{array}{ll}\text { ABDC } & \text { After bottom dead center } \\ \text { ATDC } & \text { After top dead center } \\ \text { BBDC } & \text { Before bottom dead Center } \\ \text { BMEP } & \text { Brake-mean effective pressure } \\ \text { bsNO }_{x} & \text { Brake-specific nitrogen oxides } \\ \text { BTDC } & \text { Before top dead center } \\ \text { CAD } & \text { Crank Angle Degree }\end{array}$




$\begin{array}{ll}\text { CFD } & \text { Computational fluid dynamics } \\ \mathrm{CI} & \text { Compression Ignition } \\ \mathrm{CO}_{2} & \text { Carbon dioxide } \\ \mathrm{DMUs} & \text { Diesel Multiple Units } \\ \mathrm{EEA} & \text { European Environmental Agency } \\ \text { EU } & \text { European Union } \\ \text { EVC } & \text { Exhaust Valve Closure } \\ \text { EVO } & \text { Exhaust Valve Opening } \\ \mathrm{HD} & \text { Heavy duty } \\ \mathrm{HiL} & \text { Hardware in the loop } \\ \text { IVC } & \text { Inlet valve closure } \\ \text { IVO } & \text { Inlet valve opening } \\ \text { NRMM } & \text { Non-Road Mobile Machinery } \\ \text { NRSC } & \text { Non-Road Steady Cycle } \\ \text { NRTC } & \text { Non-Road Transient Cycle } \\ \text { NOx } & \text { Nitric oxides } \\ \text { OEMs } & \text { Original equipment manufactures } \\ \text { PM } & \text { Particulate matter } \\ \text { RT } & \text { Real Time }\end{array}$

\section{References}

1. EU-Index: Deutschland bei Elektrifizierung der Bahn nur Mittelmaß; Allianz pro Schiene: Berlin, Germany, 2012. Available online: https: / /www.allianz-pro-schiene.de/presse/pressemitteilungen/2012-019-elektromobilitaet-deutschland-bei-bahnelektrifizierung-mittelmass/ (accessed on 28 January 2022).

2. Report: 'Energy Savings with Hybrid Locomotives on TEN-T Corridors'; Berlin University of Technology: Berlin, Germany, 2015.

3. Electrified Rail Network in Europe, by Country. Available online: https://www.statista.com/statistics/451522/share-of-the-railnetwork-which-is-electrified-in-europe/ (accessed on 28 January 2022).

4. Mobility and Transport. Available online: https://transport.ec.europa.eu/index_en (accessed on 28 January 2022).

5. Dittus, H.; Hülsebusch, D.; Ungethüm, J. Reducing DMU fuel consumption by means of hybrid energy storage. Eur. Transp. Res. Rev. 2011, 3, 149-159. [CrossRef]

6. Norris, J.; Ntziachristos, L.; Samaras, Z.; Zieroch, K.-H. Air Pollutant Emission Inventory Guidebook: Railways; European Environment Agency (EEA): København, Denmark, 2016.

7. Beatrice, C.; Denbratt, I.; Di Blasio, G.; Di Luca, G.; Ianniello, R.; Saccullo, M. Experimental assessment on exploiting low carbon ethanol fuel in a light-duty dual-fuel compression ignition engine. Appl. Sci. 2020, 10, 7182. [CrossRef]

8. Dalmann, T.; Menon, A. Technology Pathways for Diesel Used in Non-Road Vehicles; Internation Council on Clean Transportation: San Francisco, CA, USA, 2016.

9. Arora, N.K.; Mishra, I. COP26: More challenges than achievements. Environ. Sustain. 2021, 4, 585-588. [CrossRef]

10. Emission Standards: Europe: Nonroad Engines. Available online: https://dieselnet.com/standards/eu/nonroad.php (accessed on 28 January 2022).

11. Gao, Z.; Conklin, J.C.; Daw, C.S.; Chakravarthy, V.K. A proposed methodology for estimating transient engine-out temperature and emissions from steady-state maps. Int. J. Engine Res. 2010, 11, 137-151. [CrossRef]

12. Brooks, R.J.; Tobias, A.M. Choosing the best model: Level of detail, complexity, and model performance. Math. Comput. Model. 1996, 24, 1-14. [CrossRef]

13. Numerical Simulation for Vehicle Powertrain Development I IntechOpen. Available online: https://www.intechopen.com/ chapters / 19452 (accessed on 23 February 2022).

14. Cieslar, D.; Darlington, A.; Glover, K.; Collings, N. Model based control for closed loop testing of 1-D engine simulation models. IFAC Proc. Vol. 2012, 45, 482-489. [CrossRef]

15. Gimelli, A.; Muccillo, M. Performance assessment of a $15 \mathrm{~kW}$ Micro-CHCP plant through the 0D/1D thermo-fluid dynamic characterization of a double water circuit waste heat recovery system. Energy 2019, 181, 803-814. [CrossRef]

16. Gimelli, A.; Muccillo, M.; Pennacchia, O. Study of a new mechanical variable valve actuation system: Part I-Valve train design and friction modeling. Int. J. Engine Res. 2015, 16, 750-761. [CrossRef]

17. Gimelli, A.; Muccillo, M.; Pennacchia, O. Study of a new mechanical variable valve actuation system: Part II-Estimation of the actual fuel consumption improvement through one-dimensional fluid dynamic analysis and valve train friction estimation. Int. J. Engine Res. 2015, 16, 762-772. [CrossRef]

18. Ammendola, F.; Giardiello, G.; Gimelli, A.; Muccillo, M.; Riccio, D.; Tufano, F.; Zeppa, G. Early stage calibration of a formula SAE engine 1-D fluid dynamic model with limited experimental data. E3S Web Conf. 2020, 197, 06014. [CrossRef]

19. One-Dimensional Simulation (1D-CFD-Simulation) ISpringerLink. Available online: https://link.springer.com/chapter/10.1007/ 978-3-8348-8131-1_5 (accessed on 23 February 2022). 
20. A Hardware-in-the-Loop (HIL) Bench Test of a GT-Power Fast Running Model for Rapid Control Prototyping (RCP) Verification. Available online: https:/ / www.sae.org/publications/technical-papers/content/2016-01-0549/ (accessed on 23 February 2022).

21. Wurzenberger, J.C.; Heinzle, R.; Deregnaucourt, M.-V.; Katrasnik, T. A Comprehensive Study on Different System Level Engine Simulation Models; SAE International: Warrendale, PA, USA, 2013. [CrossRef]

22. Beatrice, C.; Capasso, C.; Costa, M.; Di Blasio, G.; Di Luca, G.; Iantorno, F.; Martoriello, G. Model based optimal management of a hybrid propulsion system for leisure boats. J. Energy Storage 2022, 46, 103896. [CrossRef]

23. Costa, M.; Martoriello, G.; Tuccillo, R. Modelling of an innovative and autonomous micro-grid based on a biomass-Solar PV hybrid power system. E3S Web Conf. 2021, 238, 02003. [CrossRef]

24. ISO 8178-4:2020; Reciprocating Internal Combustion Engines—Exhaust Emission Measurement—Part 4: Steady-State and Transient Test Cycles for Different Engine Applications. ISO: London, UK, 2020. Available online: https://www.iso.org/cms / render/live/en/sites/isoorg/contents/data/standard/07/91/79199.html(accessed on 23 February 2022).

25. VECTOR SERIES Use and Maintance. Available online: http://www.iveco.su/manuals/UseMaintanceManual-VECTORseries-L31900015E-Apr06.pdf (accessed on 23 February 2022).

26. Konstandopoulos, A.G.; Kostoglou, M.; Beatrice, C.; Di Blasio, G.; Imren, A.; Denbratt, I. Impact of combination of EGR, SCR, and DPF technologies for the low-emission rail diesel engines. Emiss. Control Sci. Technol. 2015, 1, 213-225. [CrossRef]

27. A New Approach to Integrating Engine Performance and Component Design Analysis Through Simulation. Available online: https:/ / www.sae.org/publications/technical-papers/content/880131/ (accessed on 23 February 2022).

28. Gamma Technologies, Application Manuals; Gamma Technologies: Westmont, CA, USA, 2016.

29. Chalet, D.; Yassine, M.; Migaud, J. New 0D/1D physical approach for modelling the gas dynamics behavior inside the intake system of an engine. J. Therm. Sci. 2018, 27, 394-403. [CrossRef]

30. Nikzadfar, K.; Shamekhi, A.H. An extended mean value model (EMVM) for control-oriented modeling of diesel engines transient performance and emissions. Fuel 2015, 154, 275-292. [CrossRef]

31. Yin, J.; Su, T.; Guan, Z.; Chu, Q.; Meng, C.; Jia, L.; Wang, J.; Zhang, Y. Modeling and validation of a diesel engine with turbocharger for hardware-in-the-loop applications. Energies 2017, 10, 685. [CrossRef]

32. Constructing Engine Maps for Full Vehicle Simulation Modeling. Available online: https://www.sae.org/publications/technicalpapers/content/2018-01-1412/ (accessed on 23 February 2022).

33. Nishio, Y.; Murata, Y.; Yamaya, Y.; Kikuchi, M. Optimal calibration scheme for map-based control of diesel engines. Sci. China Inf. Sci. 2018, 61, 70205. [CrossRef] 